
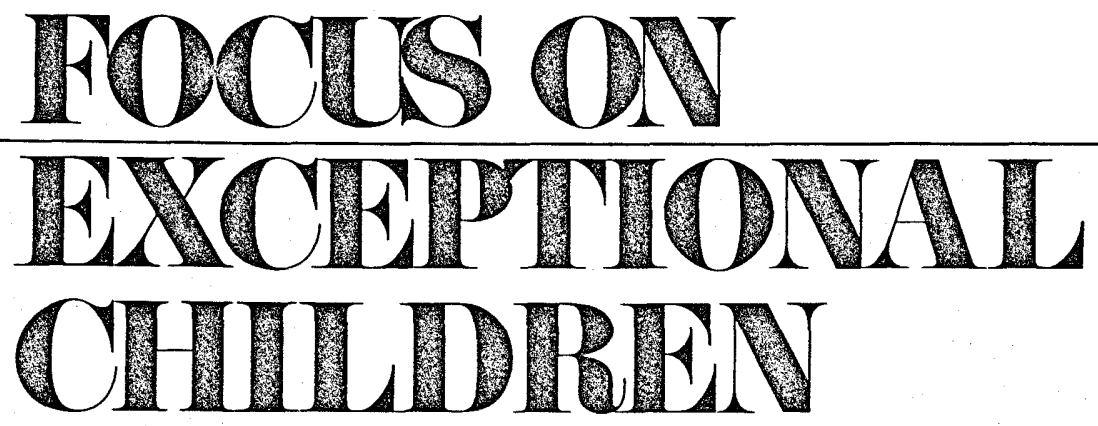

A HUMANISTIC APPROACH TO MAINSTREAMING
Mainstreaming has been popularized as the alternative to the traditional special class approach to serving exceptional children. Few people have thoroughly investigated the conceptualization and implementation of mainstreaming programs, however. Beery not only has advocated alternative programs for exceptional children, but also has affiliated with local school districts in establishing such programs. His article is a personalized account of the insights gained over a period of time in working with public school personnel in carrying out a humanistic approach to mainstreaming. He is candid and articulate, and he communicates a very clear message to educators interested in the realities of mainstreaming.

\section{MAINSTREAMING: A PROBLEM AND AN OPPORTUNITY FOR GENERAL EDUCATION}

\section{Keith E. Beery ${ }^{1}$}

Legislatures, courts, and others are pressing for "mainstreaming." What is it? Why do it? Who, how, when, where? Although I can only scratch the surface here, I urge that anyone who is considering participation in mainstreaming examine these questions in depth before starting. The greatest help I have to offer you are these questions.

What is mainstreaming? First of all, I think it is essential to discriminate between philosophy and program. Philosophically, to me mainstreaming means the valuing of human differences. It means that everyone is a teacher and that everyone is a learner. It means that all of us together are greater than any one of us or some of us. It means that heterogeneous grouping is more growth promoting, both academically and in the qualities that make us human, than is homogeneous grouping. It means the desirability of inclusion of people rather than exclusion of people. These are the solid, philosophical goals which are finding increasing support in hard data. But they are goals which, by definition, one strives toward and never fully realizes.

1. Dr. Beery is Director, Institute for Independent Educational Research, San Rafael, California. This article is based on excerpts from Models for Mainstreaming (Beery, 1972a) and The Guts to Grow (Beery et al., 1974) reprinted, with changes, by permission of the author and publisher. 
Programmatically, to me mainstreaming means a continuum of services with a conscious, monitored thrust to include everyone as much as possible (in terms of each person's welfare) with everyone else. "Everyone" includes adults as well as children, a concept not yet recognized or implemented in most mainstreaming programs I've seen. Most current programs use a simplistic program definition limited to children, some to the extreme of requiring full-time participation of all handicapped children in regular classrooms. Such definitions do not make sense to me because many children and adults suffer under them.

Why mainstream? Hopefully, the answer is implicit in the foregoing. I would add that we should not mainstream if the basic motivations are pressure or anything smacking of faddism. I fear that we may already be into a "pendulum swing" that could result in regression rather than growth. The only justification for mainstreaming must be its promise as a way to improve upon the past. Personally, I believe that a healthy concept of mainstreaming, with sensible implementation, can prove to be the most far-reaching and productive educational movement in this century. It has the potential for health revolution in our troubled educational systems. But we must make haste slowly!

As to the who, when, how, and where questions, please read on. We are happy to share experiences that may be of help to you. All we ask is that you examine these ideas critically and that you share your ideas with us.

FOCUS ON EXCEPTIONAL CHILDREN is published monthly except June, July, and August as a service to those concerned with mentally retarded and emotionally disturbed children. This journal is abstracted and indexed in Exceptional Child Education Abstracts. Subscription rates, $\$ 9.50$ per year. Copyright 1974. Love Publishing Company. All rights reserved. Reproduction in whole or part without written permission is prohibited. Printed in the United States of America. Second class postage is paid at Denver, Colorado.

\section{Executive and Editorial Offices 6635 East Villanova Place Denver, Colorado 80222 \\ Telephone (303) 757-2579}

\section{EDITORIAL BOARD}

Edward L. Meyen University of Kansas
Glenn A. Vergason Georgia State University

Richard J. Whelan University of Kansas Medical Center

Sallie Carmachel Keeney Managing Editor
Stanley F. Love Publisher

\section{THE GENERAL EDUCATION APPROACH}

There are three basic ways to include more children in the mainstream of educational life: (1) simply return them from pull-out programs, (2) have special education take the lead in identifying pupil needs and programs, and (3) have general education take the lead in increasing the individualization and personalization of instruction in regular classrooms. To me, the third alternative is the best route.

In order to support my belief that organizational development-with leadership coming from general education-is the best mainstreaming road to travel, I will need to backtrack and relate some professional history.

In Remedialdiagnosis (Beery, 1968) and Teaching Triads (Beery, 1972), I reported our efforts over a period of several years to assist children with learning and behavioral difficulties in schools. Initially, we focused upon the children themselves, using various techniques for evaluating and generating learning programs for the children. We then realized that all the understanding of a child's educational needs was of little value if his teacher did not understand these needs and what to do about them. So we began to focus our work on teachers, particularly classroom teachers.

\section{Successes and Failures}

For two years, a sophisticated multidisciplinary team was transported by means of a large mobile classroom to

\section{STATEMENT OF OWNERSHIP, MANAGEMENT AND CIRCULATION \\ Date of Filing: September 30, 1974}

Title of Publication: FOCUS ON EXCEPTIONAL CHILDREN

Frequency of Issue: Monthly except June, July and August

Location of Known Office of Publication: $6635 \mathrm{E}$. Villanova Place, Denver, CO 80222

Location of Headquarters of Publisher: 6635 E. Villanova Place, Denver, CO 80222

Name and Address of Publisher, Editor, and Managing Editor: Stanley F. Love, 6635 E. Villanova Place, Denver, CO 80222 Owner: Stanley F. Love

Extent and Nature of Circulation:

Total No. Copies Printed

Paid Circulation

Sales thru dealers, etc.

Mail Subscriptions

Total Paid Circulation

Free Distribution

Total Distribution

Office Use and Left Over

Total

I certify that the statements made by me above are correct and complete.

$\begin{array}{cc}\begin{array}{c}\text { Average No. Copies } \\ \text { Each Issue during } \\ \text { Preceding 12 Months } \\ 6,500\end{array} & \begin{array}{c}\text { Single Issue } \\ \text { Nearest to } \\ \text { Filing Date } \\ 6,500\end{array} \\ 0 & 0 \\ 5,203 & 5,364 \\ 5,203 & 5,364 \\ 500 & 500 \\ 5,703 & 5,864 \\ 797 & 636 \\ 6,500 & 6,500 \\ \text { nts made by me above are correct and } \\ \\ \text { (Signed) Stanley F. Love, Publisher }\end{array}$


elementary schools. The team worked on a daily basis with teachers of a school for one month before moving on to another school. The work was highly oriented toward practicum and seminar experiences. It was quite successful in many ways. The handicapped pupils with whom the teachers worked gained, on the average, six months in reading, mathematics, spelling, and other skills during a one-month period. These initial gains were maintained and built upon in subsequent months (O'Donnell, 1969). Teachers were highly enthusiastic about this basically "inservice" approach.

I became convinced that the multidisciplinary team was not really needed in order to achieve similar, even better results, having become terribly impressed by the talent that existed among each of the some 20 facilities with whom we worked. Perhaps all that was needed was a teacher on the staff who would have time and responsibility for being an ongoing inservice facilitator for the staff.

Therefore, during the next year, we worked with 11 elementary schools, each of which had one of their own employees (usually a special education teacher) devote 50 percent or more time to trying to be the facilitator for the "same" inservice program which our team had provided previously. The only assistance provided to each school was the part-time consultation of one of our teachers who had served as a facilitator of our mobile classroom project. We had a great deal of success with this new indirect approach. The learning rates of both handicapped and other pupils in regular classrooms increased significantly (Ohlson, 1972) and most teachers were pleased with the experience. However, we had a number of significant failures and semi-successes among these schools.

\section{The "System"}

In retrospect we realized that we had not paid enough attention to the importance of the school system. We learned that "diagnosis" and "prescription" for a child, no matter how knowledgeable, was of little value if the child's teacher did not understand or welcome this knowledge for some reason. Thus, we shifted the focus of our work from children to teachers. So far, so good. But as we worked with teachers, we began to realize that even this was of little value if the school system within which the child and teacher worked did not understand or welcome suggested innovations. We could have all kinds of insight about the child's needs, the teacher could be able and willing to do a first-class job, but to no avail, except frustration for all, if the school administration and/or other aspects of the "system" resisted needed change.
Bringing a large, high-powered outside team into a school for an intensive experience had temporarily freed the "system" in our earlier work. However, we discovered later that when the team left the scene things tended to return to "normal" within a relatively short period of time. We had been flushed with success that was not really success and had underestimated the dynamics of the system.

Thus, when we dropped the team and then went into some schools with (a) "our" project and (b) "only" a consulting teacher, we were sometimes absorbed and/or rejected by the system. In about half the schools the project was rather successful, but we were just "lucky" in these cases that certain system factors were in the project's favor.

One of the most important things that we had failed to do was to respect the principal! We had unthinkingly let our behavior say to the building leader, "We have this nifty approach; we'll appreciate your cooperation, but please don't insert your influence to change it - to make it yours." Unthinkingly, we were "saying" the same thing to the faculty.

In truth, we had always given a great deal more choice and participative planning in our work than was common in most inservice or other school projects. We just did not go far enough, probably because we were blinded by our short-term successes and because participants requested "structure." Now we understand that considerable structuring by project leaders is usually required in short-term work, whereas lasting and in-depth work usually requires a great deal of participative planning.

In short, we must individualize growth experiences for teachers, principals, and school "systems" as well as for children! If growth experiences are to be meaningful, lasting, and important, they must "belong" to the learner, not be "imposed" by someone else.

\section{The School Environment}

So there was our basic failure, the negative side of our experience coin. However, we probably would never have recognized it and would have simply blamed those "uncooperative" so-and-so's if it hadn't been for the more important positive side of our experiences. We dropped the outside team in our work, as I mentioned earlier, because we came to recognize the enormous wealth of talent and constructive motivation among the adults in schoolsteachers, principals, special service personnel, and others. Our schools are chock-full of beautiful people-people who are trying very hard to make education an enjoyable and productive experience for children. I am truly awed by 
most of the educators I have met, as people and as professionals.

However, our experiences led us to believe that schools, as presently constituted, tend to be pretty lousy places for these fine people to work! I consider it no overstatement to say that our school systems unintentionally are destroying large numbers of these educators, as people and as professionals. This statement often shocks these very educators, which further saddens me because that says that they do not even realize what is happening to them. Yet look around with fresh eyes and see the large proportion of public school educators who came into the profession full of energy, idealism, and creativity, but who are now lethargic, depressed, even bitter, and certainly resistant to change. Some are doing the last thing that they want to do-making school a dull and unproductive, if not unhappy, experience for children. About three years in the system and the honeymoon is over for most teachers, right? This is not true for all, of course, but it is true for many; it should not be true for any!

Why does this happen? I don't pretend to know all the answers to that agonizing question, but I'm convinced for good reasons born of a great deal of intimate experience with dozens of schools and hundreds of teachers that most of it boils down to a very simple but sad oversight: schools have forgotten that educators are people too. People. Just like the kids are people-deserving of respect and love. By love, I mean more than "sentiment." I don't mean "liking," for one can love without that in my book. Love means, in part, effort-effort to know a person well-effort to help him or her to be successful, to grow, to enjoy. Love means coming to value another because of his differences as well as his similarities. People who are loved grow. People who are not loved disintegrate.

If that's too philosophical, let me put it this wayeducation consists of meaningful exchanges between human beings. Schools typically are rich in human resources, but these resources are wasted because meaningful exchanges are inhibited, almost by design. People (and I'm thinking of educators in particular now) are terribly isolated from one another in schools. We couldn't have planned this deprivation better if we had consciously tried! Physical walls isolate one professional from another. Time schedules isolate. Psychological barriers, particularly authoritarian hierarchies, divide and isolate and hold off. The cruel fact is that an educator, fresh from college, is "plugged into" the system like an appliance and treated like a $\operatorname{cog}$ in a wheel, a step in a factory assembly line. People atrophy under these conditions.

\section{ORGANIZATIONAL DEVELOPMENT AND RENEWAL}

People of any age need growth environments. Nowhere is this more true than in education. If a teacher is to provide stimulation and meaning and enjoyment for her pupils, then she must be working in a stimulating, meaningful, enjoyable environment-a growth environment. Yet how is one to grow if there is no ongoing provision for personal and professional growth, if instead there is isolation, indifference, even punitiveness?

Again, our schools are rich with fine adult people and professionals. Among them, they have all the potential for meeting the needs of our handicapped and other children. The only thing needed is a means for pooling these resources so that these fine people can grow and enjoy, so that they in turn can create better growth environments for children.

Industry has recognized the need for renewal systems for quite some time. A whole body of experience and knowledge has now been built for modifying organizations so that human potential and enjoyment is maximized. Schools are just now becoming aware of this critical field, but we have some excellent leadership to tap. Richard Schmuck and others at the University of Oregon (Schmuck $\&$ Miles, 1971) are outstanding examples in this regard.

To return to our personal experiences and to mainstreaming, I now believe that concepts of organizational development are our best hope, not only for handicapped children in the mainstream, but for all children and all adults who participate in this crucial endeavor we call education. In the spring of 1971 with invaluable consultation from Alfred Brokes, who is experienced in education as well as in organizational development work, and understanding support from the Bureau for Handicapped Children, U.S. Office of Education, we launched "Project Catalyst."

Our basic goal remains the same as in the past-helping handicapped children in mainstream settings as much as possible. However, having learned from our previous mistakes as well as positive learnings, we are approaching the problem quite differently. In essence, we are asking (not telling) the educators in a variety of elementary schools that they see as their personal needs as well as what they see as the pupils' needs. We are asking them to identify their own resources, their personal and group strengths. We are asking them to identify their personal and building goals. We are asking them to create their own means for meeting their professional and pupil goals. We are asking them, in short, to design their own growth environments. 
Very importantly, we are focusing our consultation on building leaders-elementary school principals. Some people seem to think that a principalship is a diminishing role. We firmly believe that the elementary school principal is in one of the most important professional positions in our entire society. The building principal is in a position to be a tremendous positive influence upon the professional lives of the teaching staff and, therefore, upon the educational lives of children.

\section{Process Overviews}

At its simplest level graphically, the Catalyst process looks something like this:

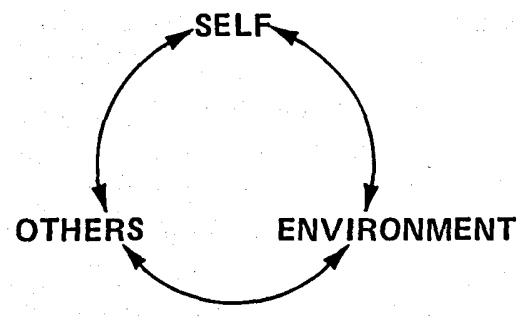

In words, two or more people agree to engage in a process of mutual growth. Each starts with self (as opposed to each trying to change the other) and asks others to provide information and moral support in this selfdevelopment effort. They create an environment (e.g., opportunities to interact constructively) which will enhance their efforts to grow together.

A little more specifically, the process looks like this:

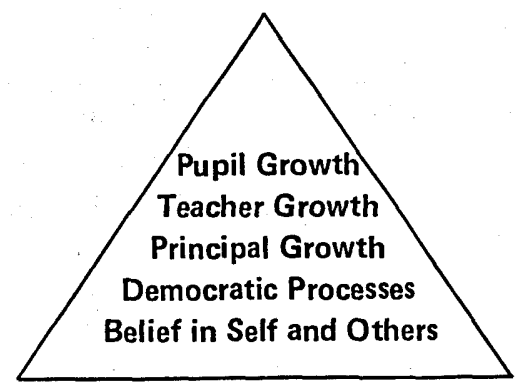

The foundation of the approach is a set of positive assumptions about people which the group will try to support in their day-to-day behaviors. Belief in self and others leads to creation of a democratic environment in which principal growth facilitates teacher growth which, in turn, facilitates pupil growth.

Finally, Figure 1 presents a somewhat expanded model of the Catalyst process showing major steps in a fairly sequentialized manner. In practice, activities often overlap one another.

Figure 1

CATALYST PROCESS

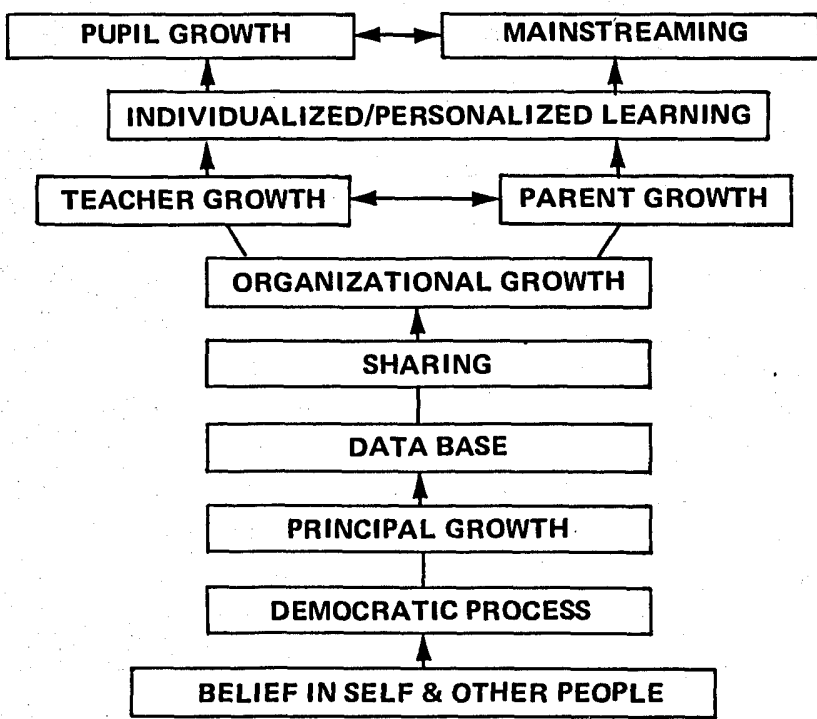

The Catalyst process might be dubbed "tough-minded humanism" because we think that love is very basic but is not enough. If we adults are to grow, just like the children, we need objectified information to help us know what we are doing well and what needs to be worked on. Data basis for group decision-making is a critical need, as is data basis for individual decision-making in a democratic environment.

Meaningful data help us to (a) feel good about our successes and (b) set goals for further improvement. Sharing, the exchange of ideas and support among peers, becomes the major method for accomplishing individual and group goals. One of the outcomes of sharing is organizational development, procedures which facilitate goal attainment. The Catalyst process particularly emphasizes development or organizational procedures that promote ongoing teacher growth.

Parent growth is considered to be a very important area in the Catalyst process, but the timing of parental involvement is a point about which many people differ. Some individuals and schools believe that parents need to be brought into the process at the very beginning. Others feel that the school needs to get itself together "in house" 
before parents and other community members are involved extensively. Whatever the timing plan that is followed, we believe that parents must eventually become deeply involved in the life of the school if the professional staff is to maximize its effectiveness and enjoyment.

As teachers and parents grow in their abilities to individualize instruction, as they help children to individualize their own instruction, it becomes possible and very desirable to include a broader range of differences in "regular" classrooms, to include presently "sidetracked" children in the mainstream of life. When a teacher freely chooses to "mainstream" in the context of a relatively strong individualized program, we have found that the program for all children is enhanced and that the teacher experiences greater job satisfaction than when teaching to a narrow range of differences.

As the educators in the project define their own strengths, needs, goals, and means for meeting them through various forms of sharing and caring, we see a rapid growth in programs for individualizing and personalizing instruction in classrooms. To be sure, some of this movement existed previously on a piece-meal basis. People were trying before, without the help of Catalyst. However, I believe that it is fair to say that there is now an increasing community of effort and support and increasing encouragement of choice and creativity on the part of teachers, increasing interpersonal regard and more rapid individual as well as group growth.

\section{Gains}

Our initial prediction was that it would take two or three years before the indirect approach of "principal growth, leading to teacher growth, leading to pupil growth" would show any payoff for the children. But, like the adults, children showed significant growth in all three areas: skills, interpersonal relations, and enjoyment. For the total group of children (kindergarten through 6th grade), the average gain in rate of learning to read, according to state-mandated achievement testing, was $32 \%$. Children who had scored in the lowest quartile in the fall of the first year, according to national norms, had an average increase in rate of learning to read of about $25 \%$.

Very importantly, the schools which had become the most democratic made the greatest gains!

After two years of working together, our 10 schools had reduced the number of children who were being pulled out of "regular" classrooms for remedial work by over $50 \%$. These children, in most cases, were doing better in "regular" classrooms than they had done before. It's not a
$100 \%$ success story, to be sure. In fact, 2 of our 10 schools have not especially changed to date. Some of the children have not made it successfully in "regular" classrooms and continue to need "special". settings. However, strong beginnings, overall, have been made.

One of our schools, which has always had about 30 intermediate-aged children in self-contained classrooms for mentally retarded, now has all of the children functioning more successfully in "regular" classrooms. The "regular" pupils and classroom teachers are happier and more productive than they were three years ago because they have developed ways to pool their talents and support for one another. As one of the teachers recently told us, "A few years ago I was ready to quit teaching; I was so frustrated and tired by the end of the week. Now I feel so proud of what I'm doing and have lots of energy to devote to myself and my family." Sure, they still have problems, but it's a whole different world that they have created for themselves!

Insofar as mainstreaming organization is concerned, I see regular classrooms developing which look a great deal like the resource rooms which have been developing in special education. There will be a clearly stated continuum of academic and social skills toward which the teacher is working. There will be objective as well as subjective means for knowing what a child knows and needs to know on this continuum. There will be a variety of means by which a child can learn these skills and identification of the means which best suit his learning style at that point. There will be large group, small group, one-to-one and independent learning activities, peer teaching, learning centers, aides, team teaching, and inclusion of resource personnel in the classroom. Not all rooms will have all these features or any of them to the same degree, since each teacher is an individual and her differences must be respected. However, there will be an increase in individualization and personalization of instruction in the classroom coming from the teacher and from his or her colleagues in their efforts to create an enhanced learning environment for themselves.

Some handicapped pupils will be functioning in the classroom full time. Others will be functioning in a resource room on a full- or part-time basis, as cooperatively determined by the classroom teacher, the resource teacher, the child, and others significant to such decisions. Very importantly, the resource teacher will be frequently working in regular classrooms as a teammate. The classroom teacher will be working in the resource room on occasion, with her entire class or with a few children. 
Most importantly, teachers will be frequently and consciously learning from one another in various practica, much as Teaching Triads (Beery, 1972).

Depending upon the particular school and its identified needs and desires, the Madison Plan, the Fail-Save plan, or some other plan modified or newly created by the staff may be utilzied to assist in the mainstreaming and other processes. There is no one best mainstreaming organization for all schools. All I have been trying to say is that the organization should be generated by the entire staff, especially classroom teachers, based upon a self-created, ongoing staff and organizational development program for the building.

\section{SUMMARY}

Who do I think should "be mainstreamed"? Everyone! We cannot, in my opinion, successfully include children unless we include ourselves and all others who have a stake in the life of a school.

How should it be done? There are no programs "out there" that can provide more than a lead for you and your school. You must create the programs that you and your children need if success is to be yours. I believe that you need to help general education be in the forefront of any changes that are made, for the sake of general education as well as for handicapped kids! I think that you will need to have great respect for data in your efforts to plan, implement, and evaluate your progress.

When? I believe that all of us must make haste slowly, being sure that the field of general education has been plowed before seeds from "special" education are planted.

Where? Where ever there is a child, parent, professional, or other person who feels alone.

\section{REFERENCES}

Beery, Keith E. Remedialdiagnosis. San Rafael, California: Dimensions Publishing Company, 1968.

Beery, Keith E. Models for Mainstreaming. San Rafael, California: Dimensions Publishing Company, 1972a.

Beery, Keith E. Teaching Triads. San Rafael, California: Dimensions Publishing Company, $1972 b$.

Beery, Keith E. et al. The Guts to Grow. San Rafael, California: Dimensions Publishing Company, 1974.

O'Donnell, Patrick A. Evaluation of the 1968.69 Remedialdiagnosis Implementation Study. Sacramento, California: State Department of Education, Title VI A, Project Report, 1969.

Ohlson, Glenn A. Evaluation of Project T.E.A.C.H. Washington, D.C.: USOE Project Report, 1972.

Schmuck, Richard A. \& Miles, Matthew E. Organization Development in Schools. Palo Alto: National Press Books, 1971.

Note: The Adapt Press, Inc. (808 West Avenue, North) of Sioux Falls, South Dakota, is now distributing the publications by Keith Beery originally published by Dimensions Publishing Company.

\section{CLASSROOM FORUM}

\author{
Edited by Alwyn H. Holloway \\ Georgia State University and \\ South Dekalb Children's Center
}

\section{PROBLEM:}

I have a child who is not learning as he should. He has been tested and is said to have learning disabilities. However, there is no space available for him in the special programs. What are some things I can do for him as far as instructional changes are concerned?

In October's Classroom Forum, the problem of physical adaptations in regular classrooms was discussed (adaptations for the hyperactive, distractible child). There are likewise many adaptations in instructional materials and management procedures that will help the child learn better. These ideas are certainly not the only ways to adapt, but perhaps they will be an aid in at least helping to initiate some changes. Here again, the teacher needs to be selective in which adaptations she utilizes, since every child would not benefit from the changes.

\section{TRICKS OF THE TRADE}

1. Structure. It is very important for the LD child to understand as much as possible about the conditions under which he is expected to work-i.e., what to expect, when to do what, etc. Consistency of structure is almost equally important. For example, if the child is expected to finish his math before having free time, this stipulation should be the same each day and should be adhered to (gradually structure can be lessened). The child then knows the consequences of his behaviors and does not have to constantly figure out and test consequences. Consistency of structure enables the child to better evaluate his own work as well as class requirements. A "Daily Assignment Card" (on a $3 \times 5$ card) which could be developed in any workable form might be of great help. The child's 
daily activities are listed according to the order in which they are to be performed. It is sometimes a good idea to follow a difficult activity (for example, reading) with an activity that the child enjoys or can do well (for example, some type of manipulative learning activity, puzzle, or free time). Such ordering of activities encourages the child to finish a difficult assignment, knowing that better things are ahead.

2. Methods of Learning. Each child learns in a different way. Since some children learn best through the auditory channels, it is helpful, at least in initial stages, to emphasize auditory skills while still working on other areas. Sometimes a child learns much more readily through visual channels, so visual cues to learning might be used. Not only is visual and auditory learning involved, but many children gain much information through tactile and kinesthetic activities. Therefore, the use of tracing, feeling, and movement in learning might prove useful to many students.

3. Reinforcement Strategies. For the child who has a difficult time learning, it is hard for him to struggle just for learning's sake. The subject of reinforcement strategies is a large one and has been reviewed in prior issues of Focus on Exceptional Children (April, 1973; May, 1973; February, 1974) and elsewhere. Therefore, let it suffice to say that some type of reinforcement strategy will be helpful to most children-not only the LD child, but most members of the entire class. Sometimes tangibles (goodies, novelty items) will be necessary, but class activities and privileges can be equally reinforcing to students.

4. Active Learning. For the hyperactive child who has much difficulty just sitting still for short periods of time, manipulative learning activities can harness some of the hyperactivity constructively. (For example, sorting pictures according to vowel sounds, spelling with cards, manipulating objects in math exercises.) The use of physical activities, both inside and outside the classroom, can be used for reinforcement of academics. Cratty (1967) provides many activities for shape recognition, spelling, and math, to mention only a few. Hap Palmer records are also excellent when structured properly.

5. Color. The use of color can bring important ideas into clearer focus for the student. Then, the use of color can be gradually faded when no longer necessary. (For example, color cuing vowels in words, using color to emphasize operations in math or to focus on troubled areas, giving starting and stopping points in writing activities, or color cuing lines if the child has difficulty staying within lines when writing.) When a child begins to lose interest in written work, giving him a colored pencil, pen, or magic marker to complete the work often refocuses his attention on the material.

6. Amount of Work Required. Because of the difficulty of some materials to the LD child, it is helpful at times to decrease the amount of work required until the child meets with some success. If the child has a fairly severe figure-ground problem or is very visually distractible, a regular workbook might be "too busy." (Since this child has much difficulty concentrating on one problem, he often sees parts of several different problems on a math page.) One solution might be to cut up the workbook and paste 1.4 problems per page on cards or plain paper. Cards, strips of poster board, or the like might be used to block from view all other visual stimuli on the page.

7. Focus of Work. To attempt to draw attention to material at hand, the following suggestions are offered. - Color-discussed previously

- Size-Increase size of important material

- Tactile materials-such as screening, sandpaper, clay pan, raised letters

- Fewer problems or work on a single page

- Manipulation of materials

- Clear, concise instructions

8. Writing Adaptations. Many children expend so much energy trying to make the fine motor movements required in writing that they are unable to really attend to the subject matter. The child might be allowed to type work. Also, older children might enjoy making tape recordings of lessons, rather than writing, if coordination problems are severe. Color cuing lines (red, green) might help the child to stop without going outside lines.

9. Elimination of Clutter on Student's Desk. Whenever possible, only the work to be done should be on the child's desk top. A check list of items completed and to be completed can be taped to the desk. He might be allowed to have IN and OUT folders or boxes to keep his work in.

Cratty, Bryant J. Movement Activities for Neurologically Handicapped and Retarded Children and Youth. New York: Educational Activities, Inc., 1967. 